\title{
PROBLEMS WITH TRIBOLOGICAL TESTINGS OF MARKETABLE OILS USING LABORATORY MODEL TEST RIGS
}

\author{
Jürgen RIGO ${ }^{1}$, Pavel KOVAČÓCY \\ ${ }^{1}$ Steinbeis-Transferzentrum An DER HochsChule MANNHEIM, KomPETENZZENTRUM \\ TRIBOlOGIE, PAUl-WITTSACK-STRAßE 4, 68163 MANNHEIM, e-mail: juergen.rigo@ stw.de \\ ${ }^{2}$ SLOVAK UNIVERSITY OF TECHNOLOGY IN BRATISLAVA, \\ FACULTY OF MATERIALS SCIENCE AND TECHNOLOGY IN TRNAVA, \\ INSTITUTE OF PRODUCTION TECHNOLOGIES, \\ Ulica JÁna BotTu 2781/25, 91724 TRNAVA, SLOVAK REPUBliC \\ e-mail: xrigoj@is.stuba.sk,pavel.kovacocy@stuba.sk \\ Received: 14.05.2018, Accepted: 25.06.2018, Published: 19.09.2018
}

\begin{abstract}
An important point in Tribology is mechanical-dynamic testing of lubricants and materials under stress and the interpretation of the results obtained therefrom. Widely-used test methods are often applied to test the performance of lubricants e.g. test results determined by tribometers should be treated carefully when using marketable oils. A closer evaluation of these results is part of this research paper.Within this study, several marketable oils were used and experimentally investigated. These were a gear oil, two engine oils, one hydraulic oil, one metal working fluid and one forming oil. There were several distinct differences. On the one hand, the used oils differ significantly in terms of their performance in the individual test methods. This is not surprising but has a clear reason in the different compositions of the lubricants resulting from their respective application. By subjecting these oils to diverse test methods with different test equipment, the results can vary widely and result in completely dissimilar results from the tests. Thus, a metalworking oil appears excellently when determining the welding force in the four-ball apparatus. In the high frequency liear oscillation tester, on the other hand, barely usable results are generated. Thus, there are two contradictory statements that should be the same.
\end{abstract}

\section{Key words}

Lubricants, base oil, additives, mechanical testing, tribological test rig 


\section{INTRODUCTION}

In technology, numerous functions can only be accomplished by active surfaces in relative motion. This is always associated with friction and wear of the relevant materials, components and structures. Friction and wear are not material properties and cannot be achieved by simple material characteristics (such as hardness or modulus of elasticity, for example). Friction and wear are "system properties". They always require the analysis and consideration of the manifold parameters of the relevant tribological system. The system engineering methodology combines methods from various disciplines of science and applies them to technology. To detect friction and wear, tribological systems are tested in the laboratory under simplified conditions. The roles of lubricants in tribological systems, are lubricating, cooling, sealing, cleaning and protecting the surfaces from wear $(18,19)$.

Classification of industrial lubricants (marketable oils) in families takes place according to the primary application profile. They fall into variety of groups, such as e.g. engine - gear - or metal working fluids and so on. The requirement profiles of industrial lubricants are defined by specifications $(14,18)$.

To influence the desired properties and to improve the qualities of the lubricants, substances, so-called additives, must be added to the base oils. Classification of the additives is based predominantly on the effect achieved and not the chemical class of substances. To reduce friction and wear, so called wear protection (Anti Wear, AW) and high-pressure (Extreme Pressure, EP) additives are added to the lubricants.

In the additives and lubricants sector, there are divergent opinions on the interactions of lubricants and additives contained in them with metal surfaces. On the one hand, there is the "old" reaction layer model $(14,19)$ and, on the other hand, the "younger" adsorption model (15). Both models can only be used with well-founded evidence.

It is difficult to make clear statements with the known models on the additives' effectiveness or their interaction with metal surfaces. The situation becomes particularly precarious when attempts are made to incorporate the findings of the literature into simulation models that are currently in widespread use. With simple coefficients of friction or wear values determined on tribological test machines, it is quite difficult to get useful results for simulation $(17,3)$. Most of the papers over the last years have been based on the formation of slidingactive reaction layers $(1,14)$.

There is no definite evidence, however represented, for both of the two models. For many phenomena in metal working (machining/forming), as well as beyond, the adsorption model seems to offer plausible explanations (17).

For the lubricant formulator, the consequence is to adjust the composition of the lubricant for the surfaces in the tribological collective. It has long been known that lubricants (even from the same production batch) can lead to different performance-related results (16).

To clarify the behavior of additives on metal surfaces, several additives or combinations of these were often investigated by means of the Brugger test, for example $(16,17,11,3)$.

In addition to these aspects, there are the general problems of tribological testing. As mentioned above, one of the most important aspects of the lubricants, additives and tribological testing technology is the question of the inter-relationships and the predictability of phenomena which occur within the tribological systems.

In addition to the complex tribological aspects of additive and metal chemistry, the mechanical-dynamic model testing of these properties and the interpretation of the results of the tests are of great importance.

It is also of a great interest to compare the results of different test methods. It can cause problems if only one method is used to clarify the effects on additive effectiveness on a given test rig for example (12). Often, results are generated with only one apparatus to support the 
existing theories or to postulate the new ones regarding the additive response in tribological testing machines.

In general, widely used test equipment is often utilized to test the performance of lubricants. Usually, these tests are carried out with standard test parameters (standardized tests according to DIN, ASTM and many other standards) which have no significant correlation with the parameters from practice. Often, a wrong system analysis is to blame. The test results obtained by tribometer tests should be therefore accepted with caution and must be proven with field tests (5). Furthermore, various test rigs provide completely different results through different contact, movement, and lubrication conditions, temperatures, loads, etc. (13).

Specifically, the testing of the tribological properties of lubricants is a wide area of lubricant classification and specification. The requirement profiles of industrial lubricants are defined by specifications. For widespread applications, there is standardization in national (DIN, ASTM) and international (ISO) standards, and classification according to the minimum requirements.

Concerning lubricant specifications, it is important to perform release testings to assess a fully developed product for its suitability in the end system. However, release testings are not suitable for development, because the individual tests are too time-consuming and costly. Therefore, it is often urgently necessary to develop suitable simpler, cheaper and faster screening test methods. These expenses for mechanical-dynamic tests are offset by those anticipated costs that would be incurred in unfunded recommendations or incorrect application of the lubricant. Thus, machine damage, repair, downtime and consequential costs quickly add up, due to increasing cross-linking of machinery, to much higher repair costs (10). Since the step from model testing to final approval examination is still very large, a better understanding of the results of standard testings is needed.

Tribological tests can be divided into different types (categories). Between the so-called field testing and model testing, there are several intermediate stages. They alltogether form a tribological test chain. In the GfT worksheet number 7 (4), the tests are divided into six individual categories.

Basically, for this division of the test chain, that of category I to category IV, the system structure of the original tribological test unit is maintained and only the stress collective in question is simplified. The benefit of the categories II and III over category I is the reproducible stress collective. From category IV down to category VI, the system structure of the test system increasingly changes - with the disadvantage of declining certainty of the transferability from test results to the practical tribological system. The advantages of the test categories IV to VI are the always more accessible tribological contact, the lower test costs and shorter test times. There are several standardized test methods for standard testing equipment. Over the years, special standards have developed for many industries that rely in part on those tests. This is acceptable when it is explicitly stated from the test method. It turns out, however, that different test methods on different machines specify the same parameters, for example the wear prevention of lubricants. 


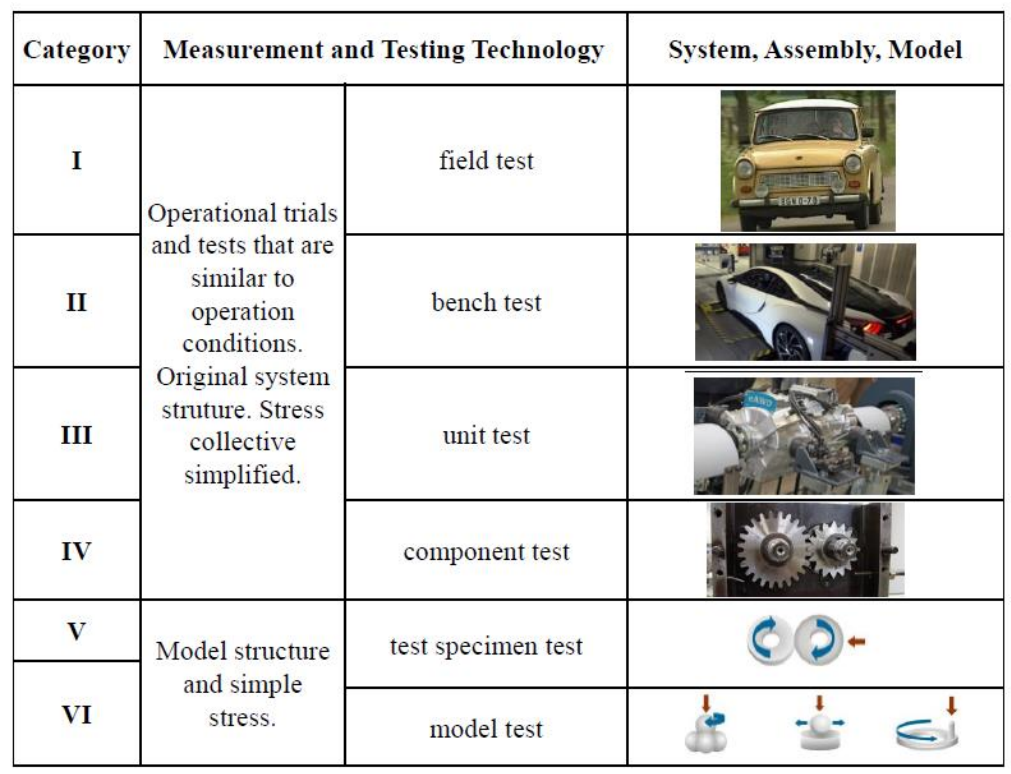

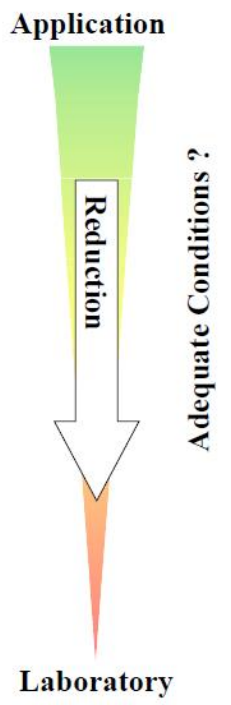

Fig. 1 Tribological test chain

To clarify the problem, the topic is briefly discussed here based on the four-ball tester. The German standardization organization DIN has defined the standards DIN 51350, which are divided into five parts. There is a variety of test methods for only one tribometer, which are supposed to generate the same statement, but whose results are not comparable. The Institute of Petroleum has established the IP 239 standard, which broadly covers the four ASTM methods, but uses a single speed. The purpose of the new standard according to ISO 20723 is to present a single standard for the evaluation of the high pressure and anti-wear properties of all types of lubricants by means of a four-ball apparatus starting from only a single speed of $1450 \mathrm{rpm}$ (8). Table 1 illustrates the testing parameters of the above-mentioned tests.

Table 1: Testing parameters of the common four-ball tester standards [ISO 20623]

\begin{tabular}{|c|c|c|c|c|c|c|}
\hline Standard & Lubricant & Type of test & Load $[N]$ & Duration & $\begin{array}{l}\text { Speed } \\
\text { [rpm] }\end{array}$ & $\begin{array}{c}\text { Temperature } \\
{\left[{ }^{\circ} \mathrm{C}\right]} \\
\end{array}$ \\
\hline ASTM D 2262 & Grease & Wear & 392 & $60 \mathrm{~min}$ & 1200 & 75 \\
\hline ASTM D 4172 & Oil & Wear & 147(A) / 392(B) & $60 \mathrm{~min}$ & 1200 & 75 \\
\hline ASTM D 2596 & Grease & Extreme Pressure & 59 up to 7848 & $10 \mathrm{~s}$ & 1770 & $18-35$ \\
\hline ASTM D 2783 & Oil & Extreme Pressure & 59 up to 7848 & $10 \mathrm{~s}$ & 1770 & $19-35$ \\
\hline IP 239 & Grease / Oil & $\begin{array}{c}\text { Extreme Pressure } \\
+ \text { Wear }\end{array}$ & 60 up to 7940 & $\begin{array}{l}\text { Wear: } 60 \mathrm{~min} \\
\text { EP: } 10 \text { or } 60 \mathrm{~s}\end{array}$ & 1450 & not specified \\
\hline DIN 51350-2 & Oil & Extreme Pressure & 2000 up to 12000 & $60 \mathrm{~s}$ & 1450 & $18-40$ \\
\hline DIN 51350-3 & Oil & Wear & $150(\mathrm{~A}) / 300(\mathrm{~B})$ & $60 \mathrm{~min}$ & 1450 & $18-40$ \\
\hline DIN 51350-4 & Grease & Extreme Pressure & 2000 up to 12000 & $60 \mathrm{~s}$ & 1450 & $18-40$ \\
\hline DIN 51350-5 & Grease & Wear & $150(\mathrm{C}) / 300(\mathrm{D}) / 1000(\mathrm{E})$ & $60 \mathrm{~min}$ & 1450 & $18-40$ \\
\hline
\end{tabular}

It should be noted that these efforts are made only for one test rig. Many other testing devices also provide many standardized test methods. Thus, on the one hand, there are problems with the comparability of the results of the methods for individual test devices.

On the other hand, there is the problem with comparability of the determined characteristics of the devices with each other. Thus, there is still no statement about the comparability of the test equipment with each other. Correlation of those tests methods with real-world applications for the performance assessment of lubricants is insufficient, since the complex relationships within a tribological system cannot be fully mapped. Yet, those tests are still in wide use. 
Practical tests and bench tests are metrologically complex, lavish and very expensive. Therefore, testing technology on replacement systems mostly reverts to the form of model tests. But this in turn is very problematic.

Standard test parameters and test methods are often used for all types of lubricants formulations. Different types of oils are tested strictly according to the standards. Depending on the composition of the lubricants (especially the EP- and AW additives), completely different rankings in testing can result, although the aim of the test method should be the same [Rigo2016]. Also often a wrong determination of which property of a lubricant or material has to be examined can take place. This means that instead of a test of the wear protection capability, a test method is used-which examines the high-pressure capacity, for example. One of the most common mistakes is an inadequate tribological system analysis. Care must be taken to ensure that tests are carried out in a mechanism-oriented manner. The mechanisms have to be identified by careful tribological system analysis (19).

Otherwise, there is a risk that you will receive a false statement. The unconsidered selection of a suitable testing machine and testing with unsuitable test parameters are also common mistakes that are often made. If then the right selection is made, it also requires a sensible selection of appropriate testing parameters $(5,9)$. Tribological systems are usually very complex, so the interactions of the tribological partners involved cannot be analysed by using just one approach. Therefore, the degrees of freedom must be reduced. For this, only simple test equipment is used for laboratoy testings.

\section{EXPERIMENTAL PART}

Commercially available lubricants have been used to illustrate the problems with the transferability of tribometer results to the behavior of marketable oils. What all the lubricants have in common is that they have long proven themselves in industrial applications and fulfill their tasks excellently. The objective of this work is to get an idea of how specific lubricants behave in each test.

\section{Accomplished test methods and test rigs for investigations}

The most common test methods for the used test rigs on the testing of lubricants are listed in Table 2.

Table 2: Test rigs and disposed test methods

\begin{tabular}{|c|c|c|c|}
\hline Test Rig & Test Method & Standard & Results and Evaluation \\
\hline XCT & Brugger & DIN 51347 part 2 & Load Carrying Capacity [N/mm²] \\
\hline VKA & Weld Load Determination & DIN 51350 part 2 & Weld Load [N] \\
\hline VKA & Wear Test & DIN 51350 part 3 & Wear Scar [mm] \\
\hline SRV & Friction and Wear Test & DIN 51834 part 2 & Wear Scar [mm], Coefficient of Friction (-) \\
\hline SRV & Load Step Test & ASTM D7421-11 & Non-Seizure Load Step [N] \\
\hline
\end{tabular}

The test conditions are standardized for a better classification of the results. Three of the most common tribometers used, pictured in Figure 2, have been utilized for many years. 


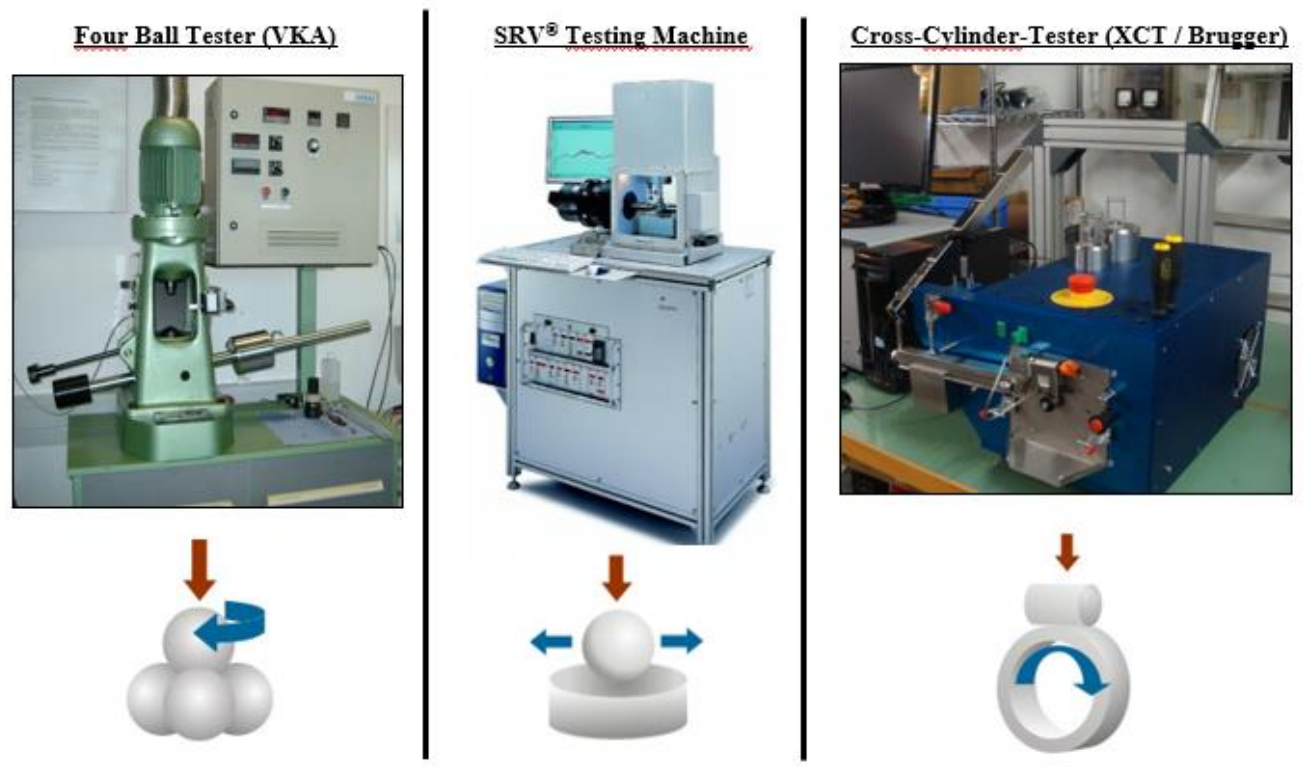

Fig. 2 Test rigs and test specimen configuration

The following Table 3 lists all important parameters of individual tests:

\begin{tabular}{|c|c|c|c|c|c|c|}
\hline \multirow{2}{*}{ Test Rig } & \multirow[b]{2}{*}{ Standard } & \multirow{2}{*}{$\begin{array}{l}\text { Sliding } \\
\text { Speed } \\
{[\mathrm{m} / \mathrm{s}]}\end{array}$} & Test Force [N] & \multirow{2}{*}{$\begin{array}{l}\text { Test } \\
\text { Temperature } \\
\text { at Test Start }\end{array}$} & \multirow[b]{2}{*}{ Test Duration } & \multirow[b]{2}{*}{ Lubrication } \\
\hline & & & $\begin{array}{c}\text { Hertzian Stress } \\
{[\mathrm{MPa}] \text { at Test Start }}\end{array}$ & & & \\
\hline \multirow{2}{*}{ VKA } & \multirow{2}{*}{$\begin{array}{c}\text { DIN } 51350 \text { part } 2 \\
\text { and } 3\end{array}$} & \multirow{2}{*}{$0.56 \mathrm{~m} / \mathrm{s}$} & $\begin{array}{l}300 \mathrm{~N} \text { (part 3) } \\
2000 \mathrm{~N} \text { (part 2) }\end{array}$ & \multirow{2}{*}{$\mathrm{RT}\left(25^{\circ} \mathrm{C}\right)$} & \multirow{2}{*}{$\begin{array}{l}1 \min (\text { part 2) } \\
60 \min (\text { part } 3)\end{array}$} & \multirow{2}{*}{$\begin{array}{c}\text { Splash } \\
\text { lubrication }\end{array}$} \\
\hline & & & $\begin{array}{l}\mathrm{P}_{\max }=3185 \mathrm{MPa} \\
\mathrm{P}_{\max }=5906 \mathrm{MPa}\end{array}$ & & & \\
\hline \multirow[t]{2}{*}{ SRV } & \multirow{2}{*}{$\begin{array}{l}\text { DIN } 51834 \text { part } 2 \\
\text { and } \\
\text { ASTM D7421-11 }\end{array}$} & \multirow[t]{2}{*}{$0.1 \mathrm{~m} / \mathrm{s}$} & $\begin{array}{c}50-300 \mathrm{~N}(\mathrm{DIN}) \\
50-2000 \mathrm{~N}(\mathrm{ASTM})\end{array}$ & \multirow[t]{2}{*}{$\begin{array}{l}50^{\circ} \mathrm{C}(\mathrm{DIN}) \\
80^{\circ} \mathrm{C}(\mathrm{ASTM})\end{array}$} & \multirow{2}{*}{$\begin{array}{l}120 \min (\mathrm{DIN}) \\
\max .53 \min \\
(\mathrm{ASTM})\end{array}$} & \multirow[t]{2}{*}{$\begin{array}{c}\text { Drop } \\
\text { lubrication }\end{array}$} \\
\hline & & & $\mathrm{P}_{\max }=1727 \mathrm{MPa}$ & & & \\
\hline \multirow{2}{*}{ XCT } & \multirow{2}{*}{ DIN 51347 part 2} & \multirow{2}{*}{$1.26 \mathrm{~m} / \mathrm{s}$} & $400 \mathrm{~N}$ & \multirow{2}{*}{$\mathrm{RT}\left(25^{\circ} \mathrm{C}\right)$} & \multirow{2}{*}{$30 \mathrm{sec}$} & \multirow{2}{*}{$\begin{array}{c}\text { Initial } \\
\text { lubrication }\end{array}$} \\
\hline & & & $\mathrm{P}_{\max }=2098 \mathrm{MPa}$ & & & \\
\hline
\end{tabular}

Briefly described here are the test methods according to Brugger, SRV and VKA. The Brugger-test is a standardized method using the friction conditions in the contact zone between friction ring and a test cylinder. It is pressed from the latter by a weight against the rotating test ring with a normal force of $400 \mathrm{~N}$. The test ring is poured over by the examined lubricant. The test duration is 30 seconds. Depending on the lubricant, a different sized wear scar (figure 3) on the stationary test cylinder results from the testing procedure. The quotient of the normal force and projected wear surface is specified as a load capacity of the lubricant according to Brugger $\left(\mathrm{N} / \mathrm{mm}^{2}\right)$.

In the SRV load step test, the test specimens are built in a test chamber of the oscillation tester and are wetted with appropriate lubricant. They are mechanically stressed at a given normal force $F_{N}$ with a predetermined test frequency $f$ and stroke $s$. The test temperature is given. The frictional forces $F_{f}$ are continuously measured; accordingly, the friction numbers $f$ become peak values determined and time-dependent written down. The test load is continuously increased in steps after a predetermined test time $t$ until scuffing occurs. The last load level 
without adhesive failure is given as the non-seizure load step. Figure 4 shows a typical wear mark. The wear test is conducted at a constant load of about $300 \mathrm{~N}$.

In the test procedure performed with the four ball tester, a rotating ball bearing ball is pressed under load on three identical but stationary balls (DIN 51350 parts 2 to 5). In the experiments according to part 2 the load is so increased until the base and counter-body cannot be separated by the lubricant and there is a welding of the balls (figure 6) due to high local temperatures. In tests according to part 3, the load is kept relatively low $(300 \mathrm{~N})$ and constant, so that it cannot come to a welding. The wear on the balls is determined according to the standard by optically measuring the resulting wear scar on the stationary balls (Figure 5).

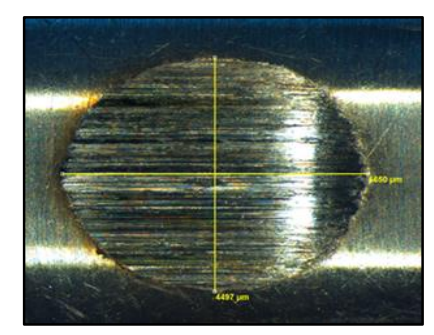

Fig. 3 Wear Scar Brugger

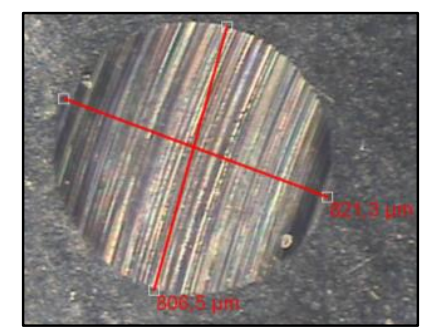

Fig. 5 Typical VKA wear scar on a stationary ball

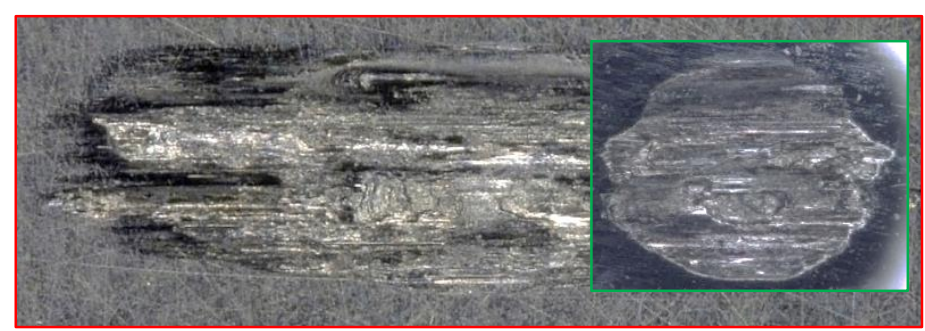

Fig. 4 Wear scar SRV (disc, ball) after adhesive failure

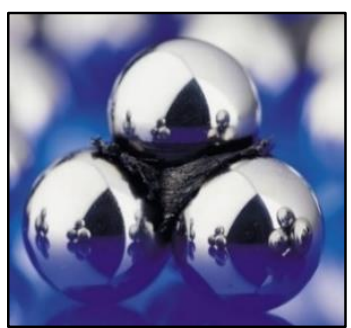

Fig. 6 Welded balls after VKA weld load test

The following lubricants were used:

\begin{tabular}{|l|l|}
\hline \multicolumn{2}{|c|}{ Table 4: Description of the tested marketable oils } \\
\hline \multicolumn{1}{|c|}{ Name } & \multicolumn{1}{c|}{ Description } \\
\hline Engine oil 1 & SAE 0W-20 \\
\hline Engine oil 2 & SAE 5W-30 \\
\hline Metal working fluid (MWF) & Usual in trade \\
\hline Forming oil & Usual in trade \\
\hline Gear oil (CLP) & CLP 220 \\
\hline Hydraulic fluid (HLP) & HLP 46 \\
\hline
\end{tabular}

\section{RESULTS}

Table 5 shows the experimental results when testing marketable oils by standardized test methods. 


\begin{tabular}{|l|c|c|c|c|c|}
\hline Table 5: Testing results of marketable oils performing standardized tests \\
\hline \multirow{4}{*}{ Lubricant } & $\begin{array}{c}\text { Brugger } \\
\text { Test Rig }\end{array}$ & \multicolumn{2}{|c|}{$\begin{array}{c}\text { Four Ball Tester } \\
\text { (VKA) }\end{array}$} & $\begin{array}{c}\text { Translatory Oscillation } \\
\text { Apparatus (SRV) }\end{array}$ \\
\cline { 2 - 6 } & $\begin{array}{c}\text { Load } \\
\text { Carrying } \\
\text { Capacity } \\
{\left[\mathrm{N} / \mathrm{mm}^{2}\right]}\end{array}$ & $\begin{array}{c}\text { Weld Load } \\
{[\mathrm{N}]}\end{array}$ & $\begin{array}{c}\text { Wear Scar } \\
\text { Diameter } \\
{[\mathrm{mm}]}\end{array}$ & $\begin{array}{c}\text { Wear Scar } \\
\text { Diameter } \\
{[\mathrm{mm}]}\end{array}$ & $\begin{array}{c}\text { Non-Seizure } \\
\text { Load Step [N] }\end{array}$ \\
\hline Forming Oil & 171.7 & 7000 & 0.38 & ----- & 300 \\
\hline $\begin{array}{l}\text { Metal working fluid } \\
\text { (MWF) }\end{array}$ & 161.8 & 8500 & 0.61 & ----- & 200 \\
\hline Gear oil (CLP) & 44.1 & 2400 & 0.45 & 0.61 & 1600 \\
\hline Engine oil 1 & 31.7 & 2200 & 0.34 & 0.76 & 2000 \\
\hline Engine oil 2 & 30.1 & 2200 & 0.35 & 0.57 & 1500 \\
\hline Hydraulic fluid (HLP) & 21.5 & 2000 & 0.35 & 0.49 & 1300 \\
\hline
\end{tabular}

The summary in Table 6 does not show absolute measurements values like in table 5 . Rather, a ranking is created. Looking at the ranking shown in this overview, it could be stated that tribometer results must be considered with extreme caution. It is obvious that the selection of the test method can lead to a completely different ranking. This could result in that the oils, which have proven themselves in practice, could be sorted out due to a simple model test.

Table 6: Ranking of marketable oils after several test methods. The red and crossed out designations mean that the lubricant did not pass the test according to the specifications

\begin{tabular}{|c|c|c|c|c|c|}
\hline \multirow{3}{*}{ 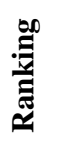 } & \multicolumn{5}{|c|}{ Testing machine and test method } \\
\hline & \multicolumn{2}{|c|}{ VKA } & \multirow{2}{*}{$\begin{array}{c}\text { Brugger } \\
\text { DIN } 51347 \text { part } 2\end{array}$} & \multicolumn{2}{|c|}{ SRV } \\
\hline & DIN 51350 part 2 & DIN 51350 part 3 & & DIN 51834 part 2 & ASTM D7421-11 \\
\hline 1 & MWF & Engine oil 1 & Forming Oil & HLP & Engine oil 1 \\
\hline 2 & Forming Oil & Engine oil 2 & MWF & Engine oil 2 & CLP \\
\hline 3 & CLP & HLP & CLP & CLP & Engine oil 2 \\
\hline 4 & Engine oil 1 & Forming Oil & Engine oil 1 & Engine oil 1 & HLP \\
\hline 5 & Engine oil 2 & CLP & Engine oil 2 & Forming Oil & Forming oil \\
\hline 6 & H世P & MWF & HLP & MWF & MWF \\
\hline
\end{tabular}

Considering these results, the following statements can be made: In the case of the shortterm tests according to Brugger and the VKA welding force determination, the group of the lubricants that are in general additivized with mostly EP-Additives (MWF for example), is very good. However, it is noticeable that these oils show very poor results in long-term tests, such as, for example, the determination of wear behaviour in the four-ball tester (DIN 51350-3). This means that both the wear tests in the SRV (DIN 51834-2) and in the VKA represent quite the same tendencies. 


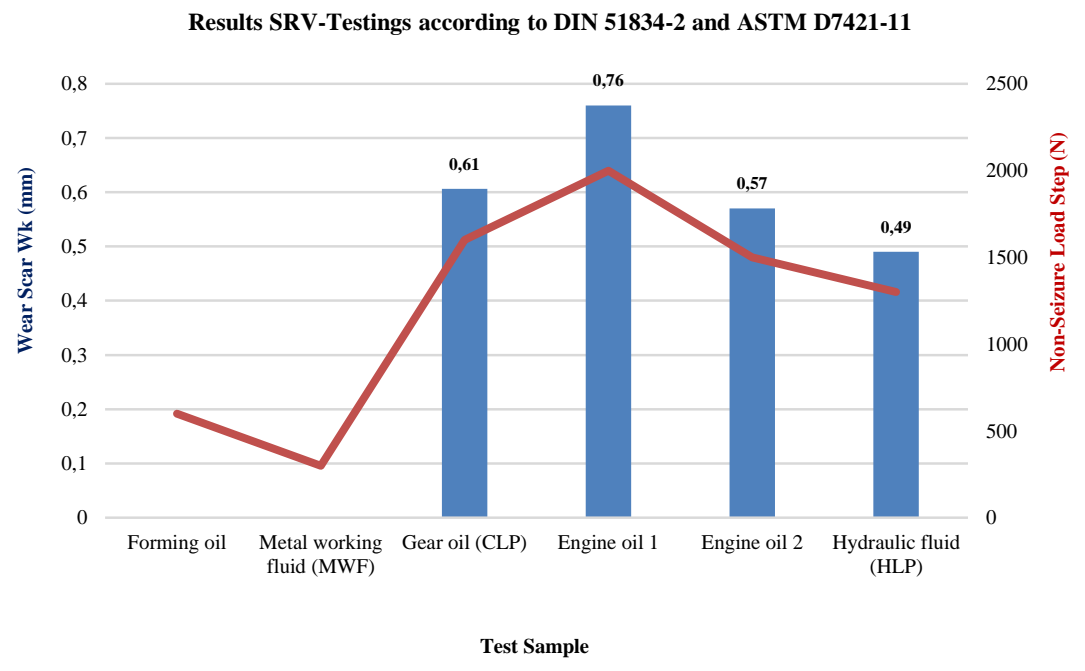

Fig. 7 SRV results of marketable oils

More wear-protection additivized samples (engine oils, hydraulic fluids) perform poorly in the load-capacity tests according to Brugger and the VKA and have only limited effects here.

It can be clearly seen that the results of the lubricants in a group are in the same range. The two oils for metalworking respectively forming lead by far the ranking.

Specifically, the hydraulic oil has here characteristic values in the range of an unadditivized base oil. Figure 7 compares the results of the two SRV test methods in a single diagram. It clearly shows the connection between load-bearing capacity and wear protection in relation to the application group of the oils. Primarily wear-resistant and less for high load-bearing capacity lubricants designed samples show good results in the wear test. But they also get good results in terms of high pressure capacity.

Surprisingly, the highly sulphurated oils which are exposed to brief and high loads in the application (forming, metalworking), don't show this behaviour at all. This means that testing in SRV is totally unsuitable for these oils, even though they should be just that feature. Thus, however, the Brugger test, the four-ball weld load test and SRV load step test would have to deliver identical results. This is not the case, as can be seen in Figures 7, 10, 11 and the ranking pictured in Table 6 .

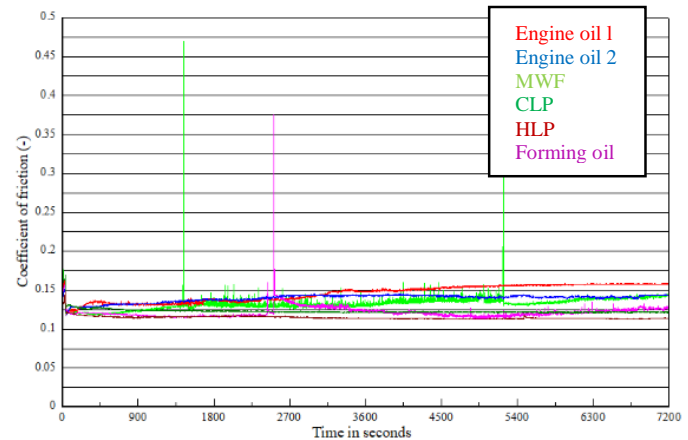

Fig. 8 SRV results of testing marketable - wear test

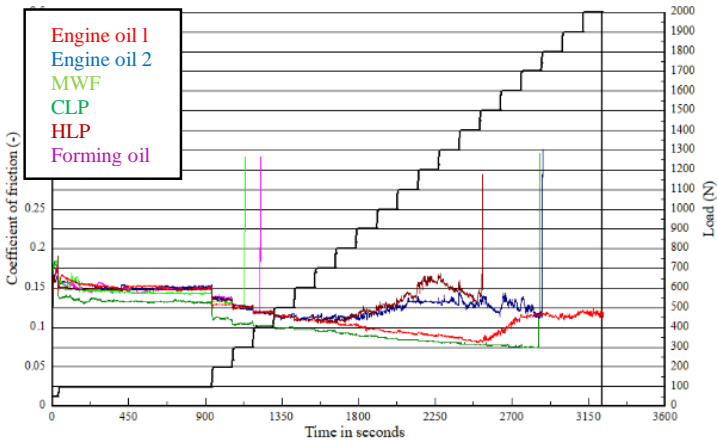

Fig. 9 SRV results of testing marketable oils EP test 
The graphs in Figures 8 and 9 show the typical coefficient of friction curves of the two SRV test methods when using the specific oils. Typically, the experiments are terminated when a coefficient of friction of 0.3 is exceeded.

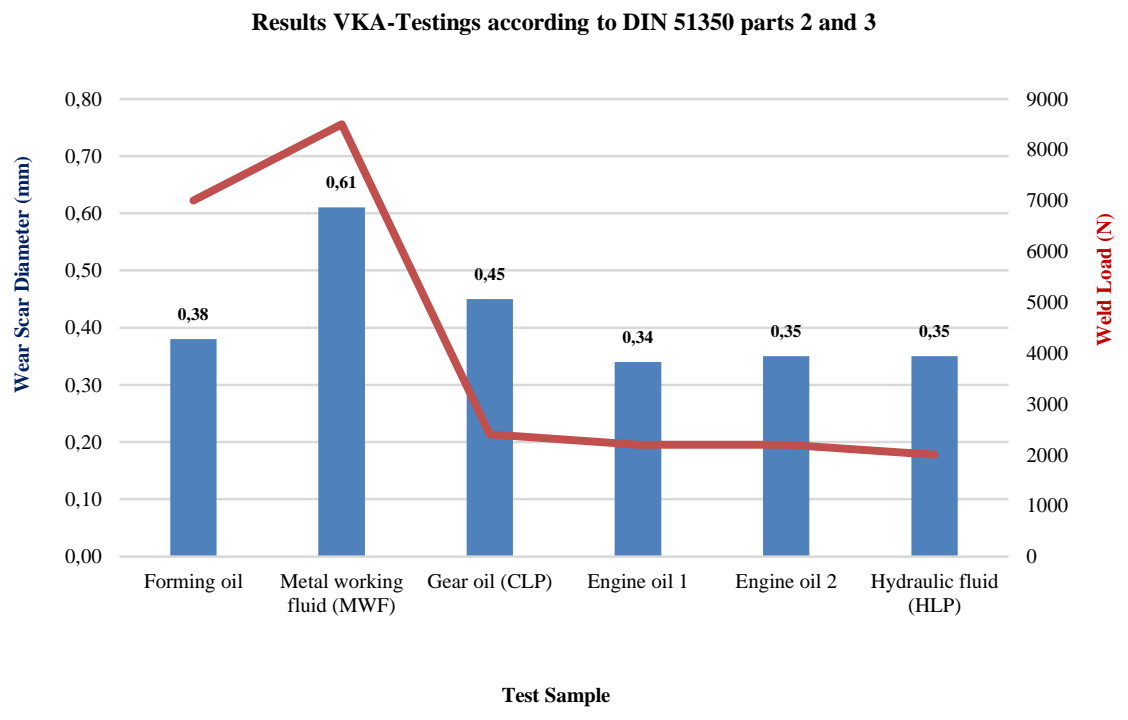

Fig. 10 VKA results of marketable oils

Regarding the Brugger results (Figure 11), the highly on high-pressure capacity additivated samples show the best effectiveness. The results are completely contrary to those achieved by testing with the SRV load step test.

Since it is the intention of the two standards to obtain a statement about the load carrying properties of lubricants, the same ranking would have to be generated in both tests. This is not the case. These observations coincide with the knowledge obtained in other projects (13). It would be necessary to develop application-specific test methods which exactly map the requirement profile from the real system to the individual model tests. If you are still in a developmental stage before the release test in the original system, there can be drawn wrong conclusions and promising patterns cannot be used further, although they certainly have potential.

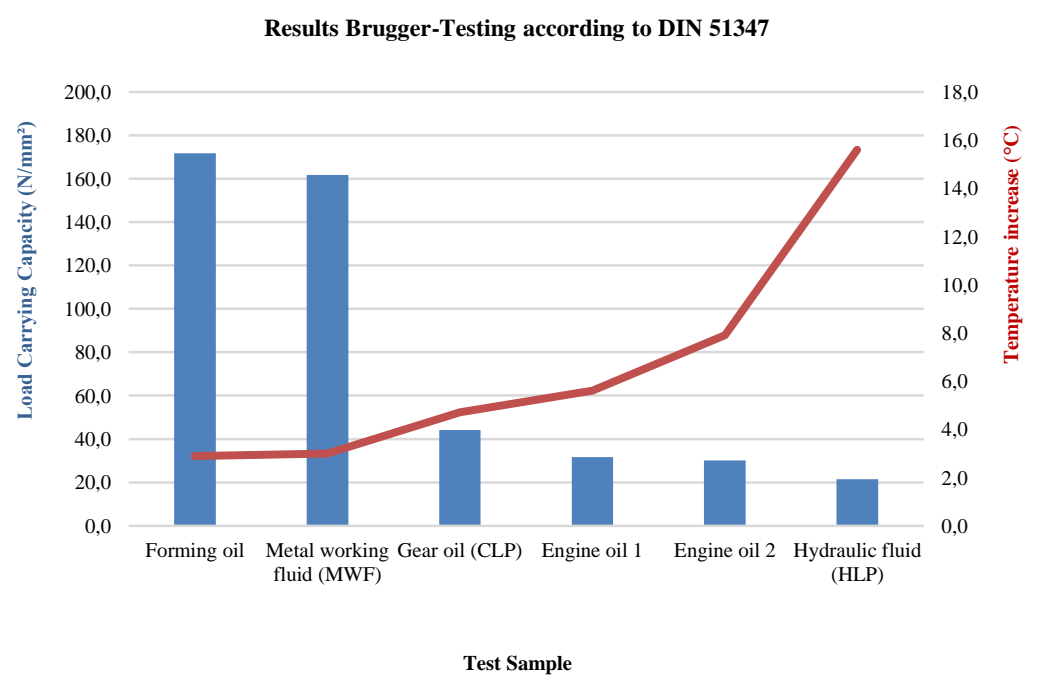

Fig. 11 Brugger results of marketable oils 


\section{CONCLUSIONS}

The question arises why, for example, the test of load carrying capacity in the SRV is not at all correlated with the determination of the welding force in the four-ball tester and the load carrying capacity test according to Brugger, although the same properties should be tested with these test methods. The concrete assessment of the performance of a lubricant by means of only one test method is therefore difficult or can develop unconsciously in a completely different direction from what is thought. Summarized, it can be stated:

$\rightarrow$ Accordance between Brugger test results and VKA weld load determination.

$\rightarrow$ VKA and SRV wear tests show partly similar results.

$\rightarrow$ VKA weld load determination and SRV load capacity tests show complete contrary results, as well as the Brugger-testings compared to the SRV load capacity test method.

Knowing to what extent different lubricants and their components behave in different tribometers should be significantly increased. However, it is still not possible to check lubricants in detail according to their application and to obtain reliable information after their application. It would be necessary to develop application-specific test methods which exactly map the requirement profile from the real system to the individual model tests.

But if you are still in a developmental stage before the release test in the original system can be drawn wrong conclusions and promising patterns cannot be used, although they certainly have potential. This requires further, intensive research.

\section{References:}

1. BARTZ, W. J. 1994. Additive für Schmierstoffe (Additives for lubricants). Expert Verlag. ISBN 978-3816909163.

2. BHARGAVA, G., GOUZMAN, I., CHUN, C.M., RAMANARAYANAN, T. A., BERNASEK, S. L. 2007. Characterisation of the "native" surface thin film on pure poly-crystalline iron: a high resolution XPS and TEM study. Applied Surface Science, 253.

3. BRINKSMEIER, E., HUESMANN, A. G., SCHULZ, J. 2012. Investigation of the mechanism between sulfur containing metal working fluids and metal surfaces by scratch experiments. Barcelona: Lubmat.

4. Gesellschaft für Tribologie (Society for Tribology) e.V. 2002. GfT Arbeitsblatt 7: Tribologie Verschleiß, Reibung, Definitionen, Begriffe, Prüfung (GfT, Moers).

5. GREBE, M. 2016. Tribometry - an underestimated science. Annual GfT-Meeting 2016, Göttingen

6. HOHENÄCKER, D. 2016. Wechselwirkungen von Schwefelträgern mit Metalloberflächen unter der Berücksichtigung von Matrixeffekten (Interactions of sulfur carriers with metal surfaces under consideration of matrix effects). Universität Bremen, Germany.

7. HOFFMANN, T., DRECHSLER, A., LEHMANN, D. 2016. Einflüsse der Oberflächenrauheit auf den Verschleißschutz von Schmierstoffen. Tribologie und Schmierungstechnik. (Influences of surface roughness on the wear protection of lubricants. Tribology and lubrication technology,) 4.

8. ISO20723 DIN EN ISO 20623. 2017. Petroleum and related products - Determination of the extreme-pressure and anti-wear properties of lubricants - Four ball method (European conditions) (ISO/DIS 20623:2017). German and English versions.

9. JÜNEMANN, H. LAUKOTKA, E.M. MICHAELIS, K. WEBER, H. 1997. Tribometry: Testing and measurement technology for friction, wear and lubrication. Contact and Study 547.

10. Klüber Lubrication. 2015. Prüfung von Schmierstoffen - Die Basis individueller Schmierstofflösungen. (Lubricant Testing - The Basis of Individual Lubricant Solutions.)

11. SCHULZ, J., BRINKSMEIER, E., MEYER, D. 2013. On the interaction of additives in metalworking fluids with metal surfaces. Lubricants 2013, 1, pp. 75-94. 
12. RIGO, J., KOVAČÓCY, P. 2017. Comparative analysis of standardized test methods on common tribological test rigs. In: International Journal of Mechanical Engineering and Automation, 4(4), pp. 130-137.

13. RIGO, J., KOVAČÓCY, P. 2018. Tribological test rig results using standardized and diversified test methods. In: 21 st International Colloquium Tribology - Industrial and Automotive Lubrication, Esslingen.

14. RUDNICK, L.R. 2009. Lubricant Additives - Chemistry and Application, $2^{\text {nd }}$ edition. New York, Basel: Marcel Decker Inc., ISBN 978-1-4200-5964-9.

15. SCHULZ, J., HOLWEGER, W. 2010. Wechselwirkung von Additiven mit Metall-oberflächen. (Interaction of additives with metal surfaces). Expert Verlag. ISBN: 978-3-8169-2921-5.

16. SCHULZ, J. FEINLE, P. HIRDT, A. RIGO, J. PFEIFFER, G. SEYFERT, C. 2011. Possibilities of the development of forming products based on test machine values. In: Annual GfT-Meeting 2011, Göttingen, Germany

17. SCHULZ, J., DECKER, B., REHBEIN, W., FEINLE, P., RIGO, J. 2013. Matrix-Effekte -Einfluss der Schmierstoffmatrix auf die Wechselwirkung von Additiven mit Metalloberflächen. (Matrix effects - Influence of the lubricant matrix on the interaction of additives with metal surfaces.) In: Tribologie und Schmierungstechnik, 2.

18. STACHOWIAK, G.W., BATCHELOR, A.W. 2014. Engineering Tribology, 4th ed. Oxford, UK: Butterworth-Heinemann. ISBN 978-0-12-397047-3.

19. Czichos, H., Habig, K.-H. 2015. Tribologie-Handbuch - Tribometrie, Tribomaterialien, Tribotechnik. 4. Auflage (Tribology Manual - Tribometry, Tribo materials, tribotechnics. $\quad 4$ th $\quad$ edition.). Berlin: Springer Verlag, ISBN 978-3-8348-1810-2.

\section{ORCID:}

Pavel Kovačócy 0000-0002-4377-7659 